\title{
LC-ToF-ESI-MS Patterns of Hirsutinolide-like Sesquiterpenoids Present in the Elephantopus mollis Kunth Extract and Chemophenetic Significance of Its Chemical Constituents
}

\author{
Gabin Thierry M. Bitchagno ${ }^{1,2, * \mathbb{C}}$, Jean Garba Koffi ${ }^{3}$, Ingrid Konga Simo ${ }^{1}$, Donald Ulrich K. Kagho ${ }^{4}$, \\ Augustin Silvere Ngouela ${ }^{1}$, Bruno Ndjakou Lenta ${ }^{3}$ and Norbert Sewald ${ }^{2}$ (i) \\ 1 Department of Chemistry, Faculty of Sciences, University of Dschang, Dschang, Cameroon; \\ simoingrid@yahoo.fr (I.K.S.); sngouela@yahoo.fr (A.S.N.) \\ 2 Organic and Bioorganic Chemistry, Faculty of Chemistry, Bielefeld University, 33501 Bielefeld, Germany; \\ norbert.sewald@uni-bielefeld.de \\ 3 Department of Chemistry, Higher Teacher Training College, University of Yaoundé I, \\ P.O. Box 47 Yaoundé, Cameroon; garbakoffijean@yahoo.fr (J.G.K.); lentabruno@yahoo.fr (B.N.L.) \\ 4 Department of Organic Chemistry, Faculty of Science, University of Yaoundé 1, P.O. Box \\ 812 Yaoundé, Cameroon; dkaghokenou@yahoo.fr \\ * Correspondence: gabin1256@gmail.com
}

check for updates

Citation: Bitchagno, G.T.M.; Koffi, J.G.; Simo, I.K.; Kagho, D.U.K.;

Ngouela, A.S.; Lenta, B.N.; Sewald, N. LC-ToF-ESI-MS Patterns of

Hirsutinolide-like Sesquiterpenoids Present in the Elephantopus mollis Kunth Extract and Chemophenetic Significance of Its Chemical Constituents. Molecules 2021, 26, 4810. https://doi.org/10.3390/molecules 26164810

Academic Editor: Valeria Patricia Sülsen

Received: 28 June 2021

Accepted: 4 August 2021

Published: 9 August 2021

Publisher's Note: MDPI stays neutral with regard to jurisdictional claims in published maps and institutional affiliations.

Copyright: (c) 2021 by the authors. Licensee MDPI, Basel, Switzerland. This article is an open access article distributed under the terms and conditions of the Creative Commons Attribution (CC BY) license (https:// creativecommons.org/licenses/by/ $4.0 /)$.
Abstract: A total of nine sesquiterpenoid lactones together with phenolic compounds and other terpenes were identified from the crude methanol extract of Elephantopus mollis Kunth. Compounds were isolated using different chromatographic techniques and their structures were determined by NMR and IR spectroscopy as well as mass spectrometry. The structures of some detected compounds were assigned based on LC-ToF-ESI-MS screening of main fractions/subfractions from flash chromatography and comparison with isolated analogues as standards. The findings revealed not only the in-source loss of water as the base peak in hirsutinolides but also the in-source loss of corresponding alcohol when the oxygen at position 1 is alkylated. The present study also draws up a complement of data with respect to hirsutinolide-like sesquiterpene lactones whose LC-MS characteristics are not available in the literature. The chemophenetic significance is also discussed. Some of the isolated compounds were reported for the first time to be found in the species, the genus as well as the plant family. The medium-polar fractions of the crude extract, also containing the larger amount of sesquiterpenoid lactones, exhibited activity both against a cancer cell line and bacterial strains. Isolated lactones were also active against the cancer cell line, while the chlorogenic derivatives also valuable in Elephantopus genus showed potent radical scavenging activity. This is the first report of cytotoxic and antibacterial activities of our samples against the tested strains and cell line. The present study follows the ongoing research project dealing with the characterization of taxa with antibacterial and antiparasitic activities from Cameroonian pharmacopeia.

Keywords: LC-MS; Asteraceae; sesquiterpenoids; lactones; cytotoxicity; antimicrobial activity

\section{Introduction}

Elephantopus mollis Kunth is a plant used for primary healthcare since ancient times. It belongs to Asteraceae and constitutes together with roughly 31 other species the group Elephantopus [1]. E. mollis and E. scaber are the most popular species of the genus [2,3]. They have been screened for their pharmacological and phytochemical profiles $[1,4,5]$. Elephantopus species are sources of a class of sesquiterpenoid lactones named elephantopustype lactones with a furane ring (C-2/C-5) in germacranolides [1-6]. They also produce glaucoside- and guaianolide-type lactones even in less amount alongside phenolic compounds and other terpenes $[1,4,5,7]$. Sesquiterpene lactones have been proven to be the active principle of the plant against various diseases $[1,4,5,7]$. 
However, the efficacy of a plant in ethnopharmacology might be highly depending on the area of collection [8]. In addition, during the chemical profiling by chromatography, low abundant compounds in the extract are most of the time lost, limiting the standardization of the plant as phytodrug. To solve such problems, efforts have been focused on highly sensitive methods such as mass spectrometry (MS), which can help to identify most of the constituents of an extract. Pure compounds isolated from the studied plant could alternatively help to establish the MS fingerprint of this group of chemicals [9]. These standards could then provide an almost exhaustive chemical profile of a taxa [9]. Accordingly, few reports are available in the literature on LC-MS characteristics of different sesquiterpenoid groups found in Elephantopus genus [9]. In our attempt to elucidate the cytotoxicity and antibacterial properties of E. mollis, we isolated and identified/detected reported sesquiterpenoid lactones by LC-MS. The results could be relevant in view of formulating the plant extract to relieve pains and diseases in less developing countries where the use of traditional medicine still prevails. The present study follows the ongoing research project dealing with the characterization of taxa with antibacterial and antiparasitic activities from Cameroonian rain forests and pharmacopeia [8,10-12].

\section{Results}

Compounds (1-19) were isolated chromatographically, their structures were established using NMR and MS techniques and compared to related compounds in the literature (Figure 1).
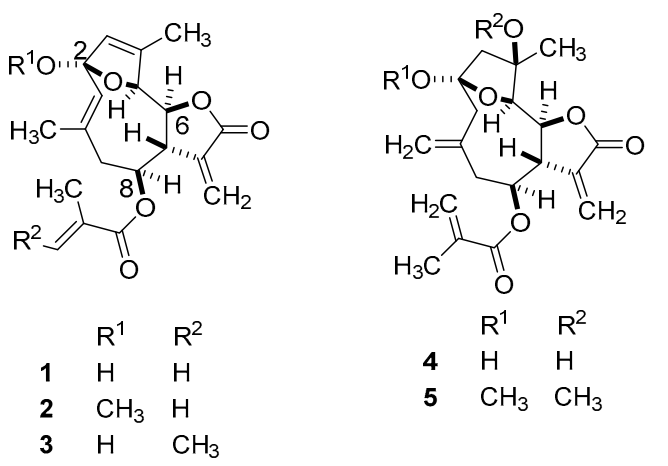

$$
\begin{array}{lll} 
& \mathrm{R}^{1} & \mathrm{R}^{2} \\
\mathbf{5} & \mathrm{H} & \mathrm{H} \\
\mathbf{5} & \mathrm{CH}_{3} & \mathrm{CH}_{3}
\end{array}
$$

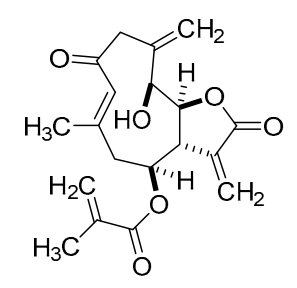

6<smiles>C=C(C)[C@@H]1[C@@H](OC(=O)C(C)=CC)C/C(C)=C\C(=O)/C=C(/C)C(O)[C@H]2OC(=O)C(=C)[C@H]21</smiles>

7

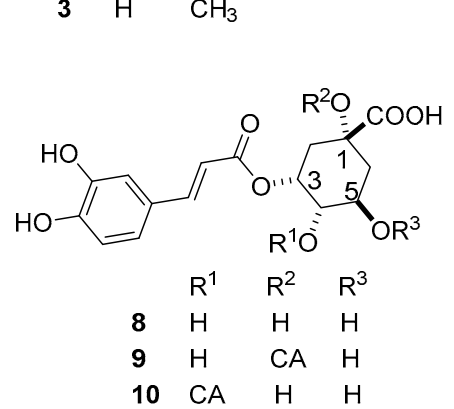<smiles>[R]c1cc(-c2cc(=O)c3c(O)cc(O)cc3o2)cc([R])c1O</smiles><smiles>[R]c1cc(OC)c([R])c(OC)c1</smiles><smiles>CC(C)(O)C1CCC2(C)CCC[C@@](C)(O)[C@H]2C1</smiles>
$\begin{array}{lll} & \mathrm{R}^{1} & \mathrm{R}^{2} \\ 11 & \mathrm{H} & \mathrm{H} \\ 12 & \mathrm{OH} & \mathrm{H} \\ 13 & \mathrm{OCH}_{3} & \mathrm{OCH}_{3}\end{array}$ $\begin{array}{rll} & \mathrm{R}^{1} & \mathrm{R}^{2} \\ 14 & \mathrm{OH} & \mathrm{COOH} \\ 15 & \mathrm{CHO} & \mathrm{OH}\end{array}$ 16<smiles>CCCCC(=O)OCC(O)CO</smiles><smiles>[R9]CC1OC(O)C(O)C(O)C1O</smiles>

$R$

17 Palmitoyl

$18 \mathrm{H}$

Figure 1. Structures of isolated compounds 1-19. 
This includes 2-deethoxy-2 $\beta$-hydroxyphantomolin (1) [5], $2 \beta$-methoxy-2-deethoxyphantomolin (2) [13], 2-deethoxy-8-O-deacylphantomolin-8-O-tiglinate (3) [14], 8-O-methacryloylelephantane (4) [5], 2,4-bis-O-methyl-8-O-methacryloy lelephantane (5), molephantin (6), molephantinin (7) [15], isochlorogenic acid (8) [16], 1,5-dicaffeoylquinic acid (9) [17], 4,5-dicaffeoylquinic acid (10) [17], apigenin (11) [18], luteolin (12) [19], tricin (13) [20], 2,6-dimethoxy-4-hydroxybenzoic acid (14) [21], 4-formylsyringol (15) [22], cryptomeridiol (16) [23], $\beta$-sitosterol-3-O- $\beta$-D-glucopyranoside-6'-O-palmitate (17) [24], $\beta$-sitosterol-3-O- $\beta$ D-glucopyranoside (18) [24] and glycerine monopalmitate (19) [24].

\subsection{LC-MS Analysis of Fractions for Structure Identification}

A non-exhaustive analysis of the LC-ToF-ESI-MS profiles of main middle-polar fractions from flash chromatography of the methanol extract led to the detection of further sesquiterpene lactones (1a and $4 \mathbf{a})$, chlorogenic acid derivatives (10a) and carbohydrates (20a-21a) (Figure 2).

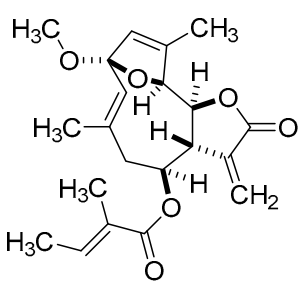

$1 \mathrm{a}$

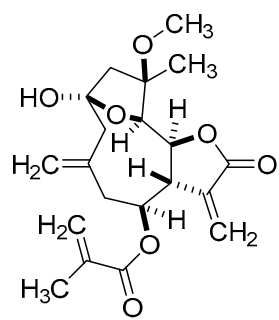

$4 a$

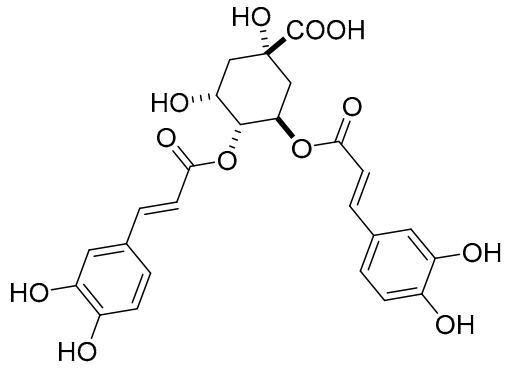<smiles>OC1CC(O)C(O)C(O)COC1O</smiles>

$20 a$
$10 a$

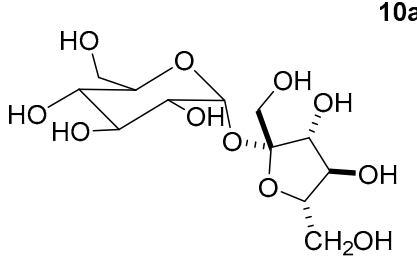

$21 \mathrm{a}$

Figure 2. Dereplicated compounds in E. mollis whole crude methanol extract.

Da Silva et al. (2020) reported the ESI-QToF-MS characterization of hirsutinolide- and glaucolide-type sesquiterpenoid lactones, the two sub-classes isolated in our study [9]. As a result, hirsutinolide skeletons give rise to an extremely low abundance of the quasimolecular ion $[\mathrm{M}+\mathrm{H}]^{+}(2-10 \% \mathrm{RA})$ and sodium adduct $[\mathrm{M}+\mathrm{Na}]^{+}(10-20 \% \mathrm{RA})$ while the base peak is the in-source water loss ion $\left[\mathrm{M}+\mathrm{H}-\mathrm{H}_{2} \mathrm{O}\right]^{+}$. These patterns are quite different for glaucolide analogues where the base peak is the protonated molecule $[\mathrm{M}+\mathrm{H}]^{+}$whereas the in-source water loss peak is absent even when the compound bears free hydroxy groups. We applied the isolated compounds $\mathbf{1}$ and $\mathbf{7}$ to ESI-MS analysis with the aim to confirm these features (Figures S1-S2, supplementary data). Under the experimental conditions, the lactones 1 afforded a base peak at $m / z 329.1$ corresponding to the ion $\left[\mathrm{M}+\mathrm{H}-\mathrm{H}_{2} \mathrm{O}\right]^{+}$ together with the quasi-molecular ion $[\mathrm{M}+\mathrm{H}]^{+}$peak of low intensity at $m / z 347.1(6 \% \mathrm{RA})$ and the sodium adduct ion $[\mathrm{M}+\mathrm{Na}]^{+}$at $m / z 369.1(4 \% \mathrm{RA})$.

Compound 2, also belonging to hirsutinolide-like lactones, showed an in-source loss of methanol $[\mathrm{M}+\mathrm{H}-\mathrm{MeOH}]^{+}$as the most intense peak, while the proton and sodium adducts were less abundant. This variation in the fragmentation patterns of hirsutinolidelike lactones $\mathbf{1}$ and $\mathbf{2}$ could result from the methylation in $\mathbf{2}$ of the sole hydroxy group in $\mathbf{1}$ (Figure S3, supplementary data). On the other hand, the mass spectrum of compound 7 presented the quasi-molecular ion $[\mathrm{M}+\mathrm{H}]^{+}$at $m / z 361.1$ as the base peak, while the sodium adduct $[\mathrm{M}+\mathrm{Na}]^{+}$and the in-source water loss ion $\left[\mathrm{M}+\mathrm{H}-\mathrm{H}_{2} \mathrm{O}\right]^{+}$were absent. The quasimolecular ion peaks of the lactones $\mathbf{1}$ and $\mathbf{2}$ were accompanied by the fragmentation peak at $\mathrm{m} / z 243.1$ also as the base peak. This ion might be generated from the loss of the methacrylic 
acid (MeacrOH, $86 \mathrm{Da}$ ) followed by elimination of $\mathrm{H}_{2} \mathrm{O}(18 \mathrm{Da})$ from 1 and $\mathrm{MeOH}$ from 2 . These patterns could help numbering hydroxy and methoxy groups in hirsutinolide-like lactones. Da Silva et al. (2020) also found similar fragmentation patterns when studying hirsutinolides under ESI conditions [9]. The fragmentation pattern is compiled in Figure 3.

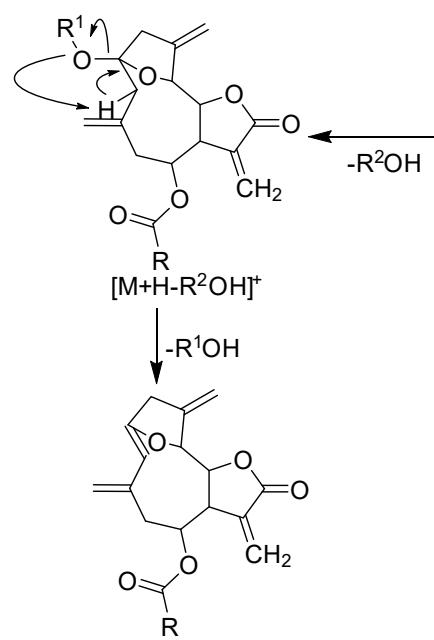

$\left[\mathrm{M}+\mathrm{H}-\mathrm{R}^{2} \mathrm{OH}-\mathrm{R}^{1} \mathrm{OH}\right]^{+}$

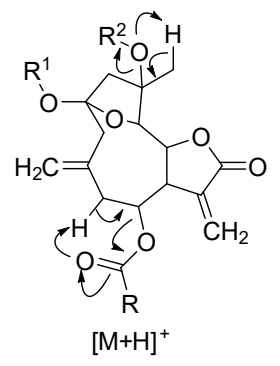

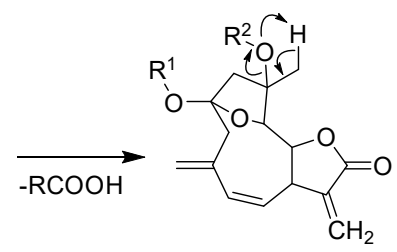<smiles>[14CH3]C(=O)O[IH+]</smiles>

$[\mathrm{M}+\mathrm{H}]^{+}$<smiles>C=C1C=CC2C(=C)CC3CC(=C)C2C3OC1=O</smiles>

$\left[\mathrm{M}+\mathrm{H}-\mathrm{RCOOH}-\mathrm{R}^{2} \mathrm{OH}-\mathrm{R}^{1} \mathrm{OH}\right]^{+}$

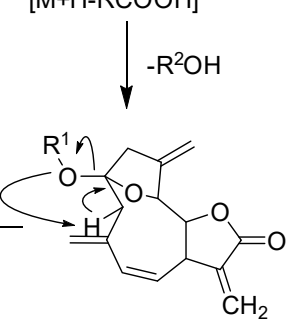

$\left[\mathrm{M}+\mathrm{H}-\mathrm{RCOOH}-\mathrm{R}^{2} \mathrm{OH}\right]^{+}$

Figure 3. Proposed fragmentation patterns in hirsutinolide-like lactones under ESI conditions.

The different main fractions from the crude extract were analyzed to detect potential non-isolated lactones of the extract. The LC-chromatogram of fraction B mainly showed four peaks (I-IV) (Figure S4, supplementary data). Peaks I-II and III-IV showed similar patterns to compound $\mathbf{1}$ for the former and to compound $\mathbf{2}$ for the latter meaning that I-II could be hirsutinolide-like lactones hydroxylated at C-2 while III-IV could correspond to methoxylated ones as previously described. The ESI spectra of compounds 1-3 were superimposable to that of peaks I, III and II, respectively. The unattributed peak IV (1a, Figure 2) has been tentatively considered as the methylated analogues of compound 2 at $\mathrm{C}-2$, with the molecular formula $\mathrm{C}_{21} \mathrm{H}_{26} \mathrm{O}_{6}$ [13].

In addition to the $\mathrm{Na}^{+}$adduct at $m / z 397.1$ (19.1\%), the LC-ESI-MS of peak IV showed the most stable peak at $m / z 343.1$ corresponding to an in-source loss of methanol $[\mathrm{M}+\mathrm{H}$ $\mathrm{MeOH}]^{+}$and the quasi-molecular ion peak $[\mathrm{M}+\mathrm{H}]^{+}$with low intensity $(17.0 \%)$ (Figure 4). Each of the peaks I-IV gave a fragment ion at $m / z 243.1$ characteristic for the above mentioned losses supporting the assignment of structures to peaks as proposed (Figure 3).

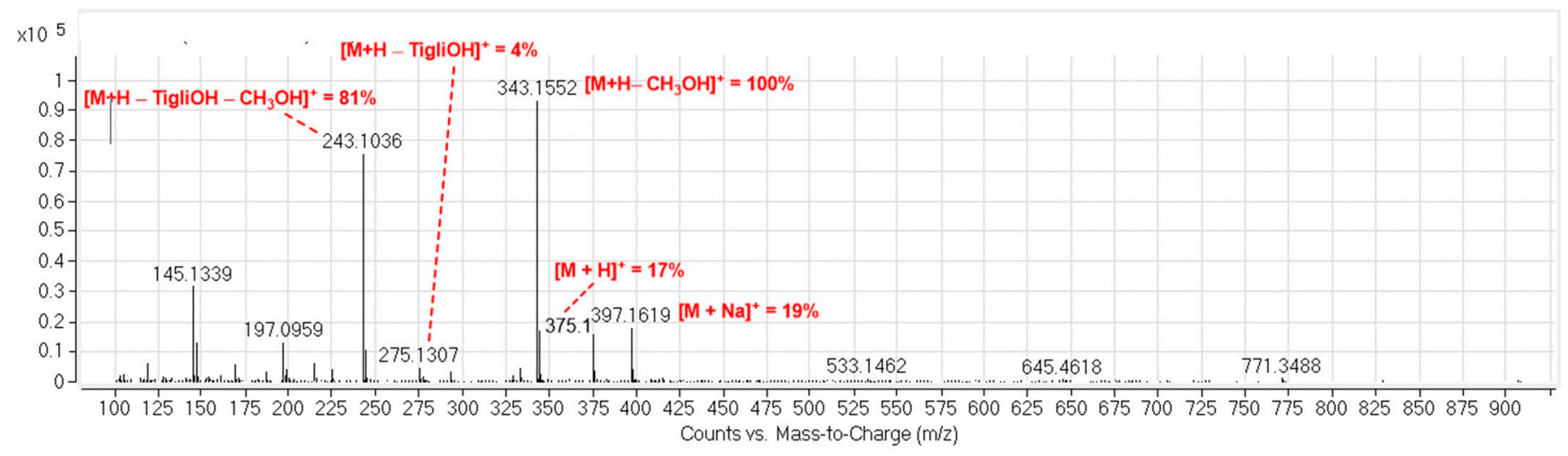

TigliOH stands for tiglic acid

Figure 4. ESI-ToF-MS of peak IV. 
The sub-fraction P1C-3 from the main fraction P1C showed instead a panel of sesquiterpenoid lactones with similar patterns to compounds 1-2. Compound 1 were present at $t_{\mathrm{R}}$ 8.317 min along with peaks VI-XII (Figure S5, supplementary data). Peak IX (compound 4) generated a base peak at $m / z 347.1$ corresponding to the dehydrated quasi-molecular ion at $m / z 365.1(63 \%$ RA) together with the sodium adduct at $m / z 387.1(52 \%$ RA). The second in-source water loss $\left[\mathrm{M}+\mathrm{H}-2 \mathrm{H}_{2} \mathrm{O}\right]^{+}$afforded a much less intense peak at $m / z 329.1(11 \%$ RA). The occurrence of two hydroxy groups in the structure of peak IX was confirmed by the fragment ions $[\mathrm{M}+\mathrm{H}-\mathrm{MeacrOH}]^{+}(m / z 279.1)$, $\left[\mathrm{M}+\mathrm{H}-\mathrm{MeacrOH}-\mathrm{H}_{2} \mathrm{O}\right]^{+}$ $(m / z 261.1)$ and $\left[\mathrm{M}+\mathrm{H}-\mathrm{MeacrOH}-2 \mathrm{H}_{2} \mathrm{O}\right]^{+}(\mathrm{m} / z$ 243.1) resulting from successive losses of two water molecules from the parent ion generated by the loss of methacrylate group. Peak XIV in the LC chromatogram of sub-fraction P1C2-2P7 (Figure S6, supplementary data) showed instead successive losses of methanol and water from the demethacrylated ion $[\mathrm{M}+\mathrm{H}-\mathrm{MeacrOH}]^{+}(m / z 293.1,16 \% \mathrm{RA})$ resulting in ions $\left[\mathrm{M}+\mathrm{H}-\mathrm{MeacrOH}-\mathrm{H}_{2} \mathrm{O}\right]^{+}$ $(m / z 275.1,16.6 \% \mathrm{RA}),\left[\mathrm{M}+\mathrm{H}-\mathrm{MeacrOH}-\mathrm{CH}_{3} \mathrm{OH}\right]^{+}(m / z 261.1,14 \% \mathrm{RA})$ and $\left[\mathrm{M}+\mathrm{H}-\mathrm{MeacrOH}-\mathrm{H}_{2} \mathrm{O}-\mathrm{MeOH}\right]^{+}(\mathrm{m} / z$ 243.1, 58\% RA). Moreover, the quasi-molecular ion $\left[\mathrm{M}+\mathrm{H}^{+}\right.$also underwent similar fragmentations affording ions $\left[\mathrm{M}+\mathrm{H}-\mathrm{H}_{2} \mathrm{O}\right]^{+}$ $(m / z 361.1,10 \% \mathrm{RA})$ and $\left[\mathrm{M}+\mathrm{H}-\mathrm{H}_{2} \mathrm{O}-\mathrm{MeOH}\right]^{+}(m / z 329.1,35 \% \mathrm{RA})$ (Figure 5). Peak XIV could derive from a monomethylation of the analogous compound 4 since both ESI spectra were superimposable. Wu et al. (2017) reported the occurrence of this isomer in $E$. mollis, namely 8-O-methacryloylisoelephantane (4a), tentatively attributed to peak XIV [5]. Peak VI also showed as base peak the quasi-molecular ion $[\mathrm{M}+\mathrm{Na}]^{+}$at $m / z 419.1$ and with similar intensity the quasi-molecular ion $[\mathrm{M}+\mathrm{H}]^{+}$at $m / z$ 397.1. Peak VI corresponds to the ion at $m / z 379.1\left[\mathrm{M}+\mathrm{H}-\mathrm{H}_{2} \mathrm{O}\right]^{+}$from the quasi-molecular ion $[\mathrm{M}+\mathrm{H}]^{+}$owing to the in-source water loss. However, the occurrence of the ion at $m / z 293.1$ from the protonated molecule suggests that the mass of the ester moiety should be $101 \mathrm{Da}$ corresponding to hydroxymethacrylate, known to occur in most sesquiterpenoid lactones. We are not aware of any elephantopus-type lactones with this substituent so far. The molecule associated to peak VI could then be a new derivative. The decalin moiety of the molecule bears one hydroxy and one methoxy groups judged by fragment ions $\left[\mathrm{M}+\mathrm{H}-\mathrm{MeacrOH}-\mathrm{CH}_{3} \mathrm{OH}\right]^{+}$ $(m / z 261.1)$ and $\left[\mathrm{M}+\mathrm{H}-\mathrm{MeacrOH}-\mathrm{CH}_{3} \mathrm{OH}-\mathrm{H}_{2} \mathrm{O}\right]^{+}(m / z$ 243.1) (Figure $\mathrm{S} 7$, supplementary data).

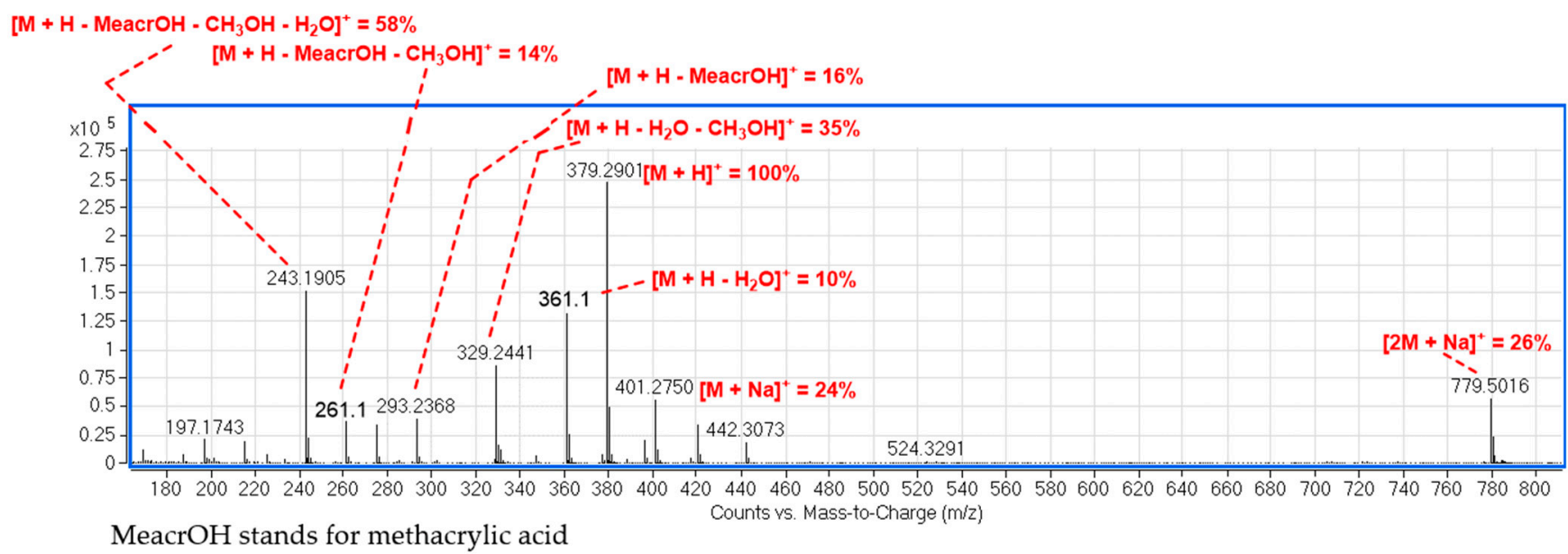

Figure 5. ESI-ToF-MS of peak XIV.

In contrast with ESI patterns of compounds 1-2, peaks VI, IX and XIV showed the double molecule- $\mathrm{Na}^{+}$complex ion $[2 \mathrm{M}+\mathrm{Na}]^{+}$at $m / z$ 815.2, $751.2(32 \% \mathrm{RA})$ and $779.2(26 \%$ RA), respectively. All these similarities, when combining ions occurring for hirsutinolides under ESI conditions and the double molecule sodium adduct ions, are indicative of similar core skeleton shared by peaks VI, XIV and compound 4 (peak IX). One could also notice a difference in relative abundances of protonated, sodium adduct and water loss ions when 
the hydroxy groups in elephantane-type skeleton, such as in $\mathbf{4}$ or $\mathbf{4 a}$, are free or substituted. This is the first report of elephantane-type lactone ESI-patterns that could serve as standards for the detection and characterization of hirsutinolide-like sesquiterpenoids in complex mixtures such as plant extracts using ESI-MS facilities.

Nonetheless, peaks VII and XII both correspond to the quasi-molecular ion [M+Na] ${ }^{+}$ $(m / z 415.1, \mathbf{V I I})$ and $m / z$ 383.1, XII $)$ as the base peak along with the quasi-molecular ion $[\mathrm{M}+\mathrm{H}]^{+}$, the ammonium adduct and the $\mathrm{K}^{+}$adduct, respectively, at $m / z 393.1$ (25.8\% RA), $m / z 410.1$ (23.6\% RA) and $m / z 431.1$ (8.3\% RA) for peak VII (Figure S8a, supplementary data) and $m / z 361.1$ (57.8\% RA), $m / z 378.1$ (25.9\% RA) and $m / z 399.1$ (4.4\% RA) for peak XII (Figure S8b, supplementary data). Peak VII generated fragments at $m / z 261.1$ (78.3\% RA) and $(m / z 243.1,80.4 \%$ RA) while peak XII fragmented into ions at $m / z 275.1$ (80.5\% RA), 257.1 (15.1\% RA) and 243.1 (12.4\% RA). These fragmentation patterns were not evidenced in each of the isolated compounds used herein as standards and isolates within the frame of our study and could therefore represent new core skeletons of sesquiterpenoid lactones in E. mollis. Unfortunately, there is a lack of sesquiterpenoid ESI-patterns in the literature which could have help to complete the identification of these molecules.

Likewise, LC-MS data were exploited to detect and identify every caffeoyl derivatives of quinic acid occurring in E. mollis. The isolated analogues (8-10) were used as standards and their ESI-MS parameters were defined. Indeed, the DAD-chromatogram of P1E at 220-280 nm showed the occurrence of four UV-active peaks which could correspond to four caffeoyl derivatives (Figure S9, supplementary data). However, only three of them were isolated (8-10). The protonated monosubstituted quinic acid (8) $[\mathrm{M}+\mathrm{H}]^{+}(\mathrm{m} / z$ 355.1) was obtained as the base peak under the analysis conditions alongside the molecule- $\mathrm{Na}^{+}$ adduct at $m / z 377.1$ with relatively low intensity $\left(10.8 \%\right.$ RA) and the bimolecular- $\mathrm{Na}^{+}$ complex $[2 \mathrm{M}+\mathrm{Na}]^{+}$at $m / z 731.1(11.0 \% \mathrm{RA})$. The in-source water loss molecule ion $[\mathrm{M}+\mathrm{H}$ $\left.-\mathrm{H}_{2} \mathrm{O}\right]^{+}$at $m / z 337.1$ was almost unobserved (0.7\% RA). For the disubstituted derivatives (9-10, 10a), the base peaks change to the in-source dehydrated molecule $\left[\mathrm{M}+\mathrm{H}-\mathrm{H}_{2} \mathrm{O}\right]^{+}$ at $m / z 499.1$ accompanied by a relatively high (10,84.3\% RA and 10a, 66\% RA) or low (9, $20.0 \%$ RA) amount of the quasi-molecular ion at $m / z 517.1$. The sodium adduct ions were always present in very low abundance (1.5-2.2\% RA) (Figure S9, supplementary data). However, considering the order of elution of dicaffeoyl isomers of quinic acid (diCA) on endcapped C18 columns available in the literature $(3,5-\mathrm{diCA}<1,5-\mathrm{diCA}<4,5-\mathrm{diCA})$ the fourth peak was assigned to 4,5-diCA (10a) [25].

The main fraction P1E was constituted in large extent by carbohydrates as proven by the MS profile of peaks ranging from $t_{R}$ 0.847-1.202 min (Figures S9-10, supplementary data) with quasi-molecular ions $[\mathrm{M}+\mathrm{Na}]^{+}$and $[\mathrm{M}+\mathrm{K}]^{+}$at $m / z 203.1$ and $219.1 ;$ at $m / z 365.1$ and 381.1, and at $m / z 527.1$ and 543.1, respectively. They correspond to a mono-, di- and trisaccharide tentatively attributed to glucose (20a) and sucrose (21a) for the first two, while the third one was not assigned. Compounds 20a and 21a were also identified by exploiting the NMR data of the mixture of these compounds. However, it was not possible to elucidate the structure of the trisaccharide (Figure 2).

\subsection{Biological Endpoints of Compounds and Fractions}

The crude extract, the flashed main fractions (P1A-P1E) and isolated compounds in high yields (1-4, 8-10) were evaluated against the cervix carcinoma cell line KB-31. The crude extract showed low activity with $\mathrm{IC}_{50}>100 \mathrm{mg} / \mathrm{mL}$. The middle-polar fractions P1B and P1C were, however, more potent to inhibit the growth of the cell line with $\mathrm{IC}_{50}=87 \mu \mathrm{M}$ for $\mathrm{P} 1 \mathrm{~B}$ and $\mathrm{IC}_{50}=21 \mu \mathrm{M}$ for P1C compared to the reference drug griseofulvin $\left(\mathrm{IC}_{50}=17-21 \mu \mathrm{M}\right)$. Among the isolated compounds, only 2 and 3 were weakly active against KB-3-1 cells with $\mathrm{IC}_{50}=22.6 \mu \mathrm{M}$ for 2 and $45.2 \mu \mathrm{M}$ for 3 .

Likewise, the samples were also screened against a panel of Gram-negative (Escherichia coli DSMZ 1058 and Pseudomonas agarici DSMZ 11810) and Gram-positive microorganisms (Micrococcus luteus DMSZ 1605, Staphylococcus warneri DSMZ 20036 and Bacillus subtilis DSMZ 704). The crude extract showed relatively low potential to inhibit the growth of the 
bacterial strains (DZI $<7 \mathrm{~mm}$ ) at concentrations of $0.5 \mathrm{mg} / \mathrm{mL}$. Nevertheless, and for the same concentrations, the middle-polar fractions P1B and P1C showed potent antibacterial properties against four of five strains tested including $P$. agarici (DZI $=15-16 \mathrm{~mm}), M$. luteus (DZI = 13-15 mm), S. warneri (DZI = 10-11 $\mathrm{mm})$ and B. subtilis $(\mathrm{DZI}=14-15 \mathrm{~mm})$. According to the MIC endpoints, $\mathrm{P} 1 \mathrm{~B}$ and $\mathrm{P} 1 \mathrm{C}$ were moderately active against $P$. agarici and B. subtilis with MIC ranging from $25-54 \mu \mathrm{g} / \mathrm{mL}$ while the activity was low against $S$. warneri (MIC > $200 \mu \mathrm{g} / \mathrm{mL}$ ) with $0.8-0.0015 \mathrm{mg} / \mathrm{mL}$ for each one. Conversely, fractions P1A and P1D showed moderate activity with DZI of $8 \mathrm{~mm}$ against E. coli and B. subtilis for P1A and DZI of $8-9 \mathrm{~mm}$ towards B. subtilis and P. agarici for P1D. The other strains were not sensitive to the tested samples including P1E. Our results were compared to those of gentamycin (reference drug), DZI $=17-21 \mathrm{~mm}$ at $0.5 \mathrm{mg} / \mathrm{mL}$ and $\mathrm{MIC}=1.6-2.1 \mu \mathrm{g} / \mathrm{mL}$. Likewise, only compound 2 showed a low activity against P. agarici DSMZ 11810 (DZI = 9 mm), M. luteus DMSZ 1605 (DZI = $7 \mathrm{~mm}$ ) and B. subtilis DSMZ 704 (DZI = $8 \mathrm{~mm}$ ). The isolated compounds were also screened for their scavenging effects against the radical DPPH. Amongst the tested samples, only compounds $\mathbf{8}$ and $\mathbf{1 0}$ displayed moderate activity with $\mathrm{IC}_{50}$ of 118 and $34 \mu \mathrm{g} / \mathrm{mL}$, respectively, compared to the reference drug trolox $\left(\mathrm{IC}_{50}=20 \mu \mathrm{g} / \mathrm{mL}\right)$. The absence of activity of compound 9 could be related to its insolubility in DMSO used for these assays as solvent.

\section{Discussion}

To date, more than 20 sesquiterpenoid lactones have been reported from Elephantopus mollis worldwide $[1,4,5,13,15,26]$. Chemophenetic uses chemical ingredients to define new clades that were previously not recognized or cannot be defined based on morphology [27]. In general, germacranolides and guaianolides are the chemophenetic markers of the studied plant genus $[1,4,5,13,15,26,28]$. Nine of them were identified or detected in the frame of our study, while compound 3 is being reported for the first time in the species and even in the genus Elephantopus. When comparing Cameroonian and Chinese species, one could highlight that seven of the lactones encountered so far were unique in the Chinese species while three were present only in the Cameroonian variant $[5,13,15]$. The Chinese species highlighted derivatives where substituents such as ethoxy at C-4 in compound 4 or angelate or tiglate at C-8 in compound 6 instead of hydroxy and acrylate, respectively, and a second lactone moiety due to the oxidized C-15/C-2 positions or the methoxylation of the $\alpha-$ methylene butyrolactone in 1 and 2 [5]. Some sesquiterpenoid skeletons already relayed in the literature such as guaianolide-type sesquiterpene lactones were not encountered in the present study. Our study is also highlighting the occurrence of an elanane-type sesquiterpene, compound 16, in the genus Elephantopus. This class of sesquiterpenes has been reported in some species of the Asteraceae plant family including Vernonia.

Our study also points out the occurrences of phenolic acids (14-15), flavonoids (11-13) and quinic acid derivatives (8-10) in Elephantopus species. Apart from compound 10 reported in E. mollis and compounds 8, $\mathbf{1 1}$ and $\mathbf{1 2}$ reported in E. scaber, each of these phytoconstituents are herein reported for the first time in the genus Elephantopus [28,29]. Methoxylated flavonoids are abundant in Asteraceae species while dicaffeoylquinic acids are scarce [24]. The occurrences of phenolic acids in E. mollis could be related to the presence of quinic acid since the latter is an intermediate in the biosynthesis of the former. Some chemophenetic markers of Asteraceae plant species namely the steroids 17, the carbohydrates 21a and the monoglyceride 19, were also elucidated [24]. The monoglyceride was isolated for the first time in the studied genus.

Overall, the samples were moderately active against both bacterial strains and cancer cell line used. The studied plant and sesquiterpene lactones are reputed for their anticancer and anti-inflammatory activities because of the $\alpha$-methylene- $\gamma$-butyrolactone moiety in their structures $[5,6,8,13,15]$. The $\mathrm{MeOH}$ extract of $E$. mollis has been reported to exhibit significant activity against a panel of colorectal, liver and breast carcinoma [30]. We report herein for the first time the cytotoxicity of the plant towards the cervix carcinoma cell line KB-3-1. The results obtained from the middle-polar main fractions P1B and P1C were 
similar to those reported for the EtOAc extract of E. mollis against the liver carcinoma HepG2 [3]. Compounds 2, 4a, 3 and 7 have been reported to be active against leukemia K562 and HL-60 and neuroblastoma B104 cell lines with $\mathrm{IC}_{50}$ less than $5 \mu \mathrm{M}[13,15,31]$. As for the extract, this is the first report on the cytotoxicity of both main fractions and sesquiterpenoid lactones against the cancer cell lines KB-3-1. Likewise, we highlight here for the first time the antibacterial activity of the samples against the tested strains.

Nonetheless, only disubstituted quinic acid shows antiradical scavenging effect toward DPPH probably due to caffeoyl moieties as indicated in the literature. The radical scavenging activity in the chlorogenic series increased with the number of caffeoyl substituents. Compound $\mathbf{1 0}$ was the most active antioxidant constituent as reported in the literature [28]. The other sesquiterpenes and compounds were not active. Our results confirm readily data available in the literature on the study plant E. mollis $[13,15,26,32]$. The active constituents of this plant have been identified to sesquiterpenoid lactone which is known to bind sulfhydryl-containing enzymes and proteins in pathogens resulting in a programmed death of organisms [13,15,26,32]. Apart from their antioxidant capacities, caffeoyl derivatives of quinic acids are well-known for their antiviral potency and extracts of E. scaber have been already patented to alleviate virus form of symptoms of diseases [33].

\section{Materials and Methods}

\subsection{General Experimental Procedures}

Electrospray ionization (ESI) mass spectra were recorded on a 1200-series HPLCsystem or a 1260-series Infinity II HPLC-system (Agilent-Technologies) with binary pump and integrated diode array detector coupled to an LC/MSD-Trap-XTC-mass spectrometer (Agilent-Technologies) or an LC/MSD Infinity lab LC/MSD (G6125B LC/MSD). High resolution mass spectra were recorded on a Micromass-Q-ToF-Ultima-3-mass spectrometer (Waters) with LockSpray-interface and a suitable external calibrant. The mobile phase used for the LC-MS comprised gradients of acetonitrile-water (containing $0.1 \%$ formic acid). UV-Vis spectra were recorded on an Evolution $201 \mathrm{UV}-$ Visible Spectrophotometer (Thermo Scientific) and infrared (IR) spectra on a FTIR-spectrometer (Bruker Tensor 27) equipped with a diamond ATR unit and are reported in terms of frequency of absorption in $\mathrm{cm}^{-1}$. NMR spectra were recorded on a Bruker Avance III $500 \mathrm{HD}\left({ }^{1} \mathrm{H}: 500 \mathrm{MHz},{ }^{13} \mathrm{C}: 126 \mathrm{MHz}\right)$ or Avance $600\left({ }^{1} \mathrm{H}: 600 \mathrm{MHz},{ }^{13} \mathrm{C}: 151 \mathrm{MHz}\right)$. Chemical shifts $\delta(\mathrm{ppm})$ are reported relative to residual solvent signal and/or tetramethylsilane (TMS). 2D spectra (COSY, HMQC, $\mathrm{HMBC}$ ) and DEPT-135 spectra were used for signal assignment.

Chromatographic purification of compounds was performed on silica gel (35-70 $\mu \mathrm{m}$, Acros Organics) and Sephadex LH-20. Automated column chromatography was also performed on a Büchi Reveleris ${ }^{\circledR}$ X2 with a binary pump and ELSD Detector using flash up column of $4 \mathrm{~g}, 12 \mathrm{~g}$ and $24 \mathrm{~g}$, depending on the sample mass, or a Biotage Snap Ultra C18 column with a gradient at various flow rate. Thin-layer chromatography (TLC) was carried out on silica plates (TLC Silica $60 \mathrm{~F}_{254}$ by Merck) and spots were detected by spraying with $20 \% \mathrm{H}_{2} \mathrm{SO}_{4}$ followed by charring at $100{ }^{\circ} \mathrm{C}$.

Analytical LC-MS was performed on an Agilent 6220 ToF-MS with a Dual ESI-source, 1200 HPLC system with autosampler, degasser, binary pump, column oven, diode array detector and a Hypersil Gold C18 column $(1.9 \mu \mathrm{m}, 50 \times 2.1 \mathrm{~mm})$ with a gradient (in $11 \mathrm{~min}$ from $0 \% \mathrm{~B}$ to $98 \% \mathrm{~B}$, back to $0 \% \mathrm{~B}$ in $0.5 \mathrm{~min}$, total run time $15 \mathrm{~min}$ ) at a flow rate of $300 \mu \mathrm{L} / \mathrm{min}$ and column oven temperature of $40^{\circ} \mathrm{C}$. HPLC solvent A consists of $94.9 \%$ water, $5 \%$ acetonitrile and $0.1 \%$ formic acid, solvent $\mathrm{B}$ of $5 \%$ water, $94.9 \%$ acetonitrile and $0.1 \%$ formic acid. The mass spectra are recorded in both profile and centroid mode with the MassHunter Workstation Acquisition B.04.00 software (Agilent Technologies, Santa Clara, CA, USA). MassHunter Qualitative Analysis B.07.00 software (Agilent Technologies, Santa Clara, CA, USA) was used for processing and averaging of several single spectra. 


\subsection{Plant Material}

The whole plant of Elephantopus mollis was collected on the savanna hills of Bamendjing (Mbouda) in the western Region of Cameroon in December 2019. The identification was performed by Mr. Victor Nana, an experienced botanist, at the Cameroon National Herbarium (Yaoundé) by comparison with the voucher specimen kept under the voucher number 35121/HCN.

\subsection{Extraction and Purification}

Dried materials of Elephantopus mollis $(1.0 \mathrm{~kg})$ were ground and macerated with methanol $(3 \times 5 \mathrm{~L}, 72 \mathrm{~h}$ each) at room temperature to yield a semi-solid crude extract $(110.0 \mathrm{~g})$ after removal of the solvent under reduced pressure on a rotary evaporator. A portion $(100.0 \mathrm{~g})$ of this extract was flashed over an open silica gel column chromatography with gradients of $\mathrm{Et}_{2} \mathrm{O}$-acetone then acetone-MeOH. In this case, 70 fractions of $200 \mathrm{~mL}$ each were collected and combined based on their TLC profiles (using mixtures of $\mathrm{Et}_{2} \mathrm{O}$ acetone 85:15, 70:30, 30:70) into five main fractions coded P1A-P1E (P1A: 1-8; P1B: 9-18; P1C: 19-40; P1D: 41-53; P1E: 54-70). Fraction P1A (5.1 g) contained mostly lipids and was not further investigated. Fraction P1B ( $4.0 \mathrm{~g})$ was flashed on a normal phase middle pressure liquid chromatography (NP-MPLC) with gradients of $\mathrm{Et}_{2} \mathrm{O}-\mathrm{EtOAc}$. Compound 3 was eluted at 77-80 min. Fraction P1C (1.5 g) was flashed over an open silica gel column chromatography with gradients of $\mathrm{Et}_{2} \mathrm{O}$-acetone and yield 100 fractions of $100 \mathrm{~mL}$ each, collected and combined base on their TLC profiles (using mixtures of Et ${ }_{2} \mathrm{O}$-acetone 85:15, 70:30, 30:70) into four main sub-fractions coded P1C1-P1C5. Each of these fractions was flashed on a NP-MPLC with gradients of Et $t_{2} \mathrm{O}-\mathrm{EtOAc}$. P1C1 led to the isolation of compound 19. P1C2 gave rise to compounds 1 at $t_{\mathrm{R}} 7-8 \mathrm{~min}, 15$ at $t_{\mathrm{R}} 10 \mathrm{~min}$ and 16 at $t_{\mathrm{R}}$ 11-15 min while the remaining mixtures were each also flashed under the same conditions with NP-MPLC. Compound 14 was eluted at $t_{\mathrm{R}} 12 \mathrm{~min}$; the mixture of 6 and 7 at $t_{\mathrm{R}} 40$ $43 \mathrm{~min}$ and compound 4 at $t_{\mathrm{R}} 53-55 \mathrm{~min}$. The same method applied to the remaining sub-fractions was not conclusive. Fraction P1D was treated as was P1C through an open column chromatography with gradients of $\mathrm{Et}_{2} \mathrm{O}$-acetone prior to NP-MPLC purification with a gradient of DCM-EtOAc. Amongst the main sub-fractions collected, only P1D-3 were conclusive affording compounds 2 and 11-13. The steroids 17 and 18 were eluted from the open-column chromatography of P1D. Fractions P1E separated on an open silica gel column chromatography with gradients of DCM-MeOH yielded four main subfractions P1E1-P1E4. P1E1 and P1E2 gave relatively same constituents as P1D. P1E3 was further chromatographed on a reversed-phase MPLC with gradients of acidified ACN$\mathrm{H}_{2} \mathrm{O}$. Compounds 8-10 were eluted at $t_{\mathrm{R}} 47,49$ and $57 \mathrm{~min}$, respectively. The remaining compounds (1a, 4a, 10a, 20a, 21a) were detected and analyzed on LC-MS profiles.

\subsection{Bioactivity}

The antibacterial activity of some isolated compounds was carried out by using the agar disk diffusion method to determine the diameter zone of inhibition (DZI) against five bacteria including two Gram-negative (Escherichia coli DSMZ 1058 and Pseudomonas agarici DSMZ 11810) and three Gram-positive (Micrococcus luteus DMSZ 1605, Staphylococcus warneri DSMZ 20036 and Bacillus subtilis DSMZ 704) strains [10,11]. The microorganisms were provided by DSMZ (German Collection of Microorganisms and Cell Cultures).

The cytotoxicity assay was performed with the human cervix carcinoma cell line KB-3-1 as previously reported [10,11]. The KB-3-1 cells were provided by DSMZ (number ACC 158) and cultivated as a monolayer in DMEM (Dulbecco's modified Eagle medium) with glucose $(4.5 \mathrm{~g} / \mathrm{L})$, L-glutamine, sodium pyruvate and phenol red, supplemented with $10 \%$ (KB-3-1) foetal bovine serum (FBS). On the day before the test, the cells (70\% confluence) were detached with trypsin-ethylenediamine tetraacetic acid (EDTA) solution $(0.05 \% ; 0.02 \%$ in DPBS) and placed in sterile $96-$ well plates in a density of 10,000 cells in $100 \mu \mathrm{L}$ medium per well. The dilution series of the compounds were prepared from stock solutions in DMSO of concentrations of $1 \mathrm{mM}$ or $10 \mathrm{mM}$. The stock solutions were diluted 
with culture medium (10\% FBS) at least 50 times. Some culture medium was added to the wells to adjust the volume of the wells to the wanted dilution factor. The dilution prepared from stock solution was added to the wells and each concentration was tested in six replicates. The control contained the same concentration of DMSO as the first dilution. After incubation at $37^{\circ} \mathrm{C}$ and $5.3 \% \mathrm{CO}_{2}$-humidified air for $72 \mathrm{~h}, 30 \mu \mathrm{L}$ of an aqueous resazurin solution $(175 \mu \mathrm{M})$ was added to each well. The cells were incubated for $6 \mathrm{~h}$ at the same conditions. Thereafter, the fluorescence was measured. The excitation was affected at a wavelength of $530 \mathrm{~nm}$, whereas the emission was recorded at $588 \mathrm{~nm}$. The $\mathrm{IC}_{50}$ that is the values equal the drug concentrations, at which vitality is $50 \%$, were calculated as a sigmoidal dose response curve using GRAPHPAD PRISM 4.03. The antioxidant activity of compounds using DDPH was determined according to the methods described by Nguemo et al. 2020 [34].

Supplementary Materials: LC chromatograms and MS spectra (Figures S1-S10) as well as NMR spectra of standards listed in the text (Figures S11-S36) are available as supporting information. Figure S1: ESI-TOF-MS of compound 1., Figure S2: ESI-TOF-MS of compound 7., Figure S3: ESITOF-MS of compound 2., Figure S4: LC chromatogram of main fraction B., Figure S5: LC profile of subfraction C3 and ESI-TOF-MS of compound 4., Figure S6. LC chromatogram of sub-fraction P1C-C2-2P7., Figure S7. ESI-TOF-MS of peak VI., Figure S8. LC chromatogram of (a) peak VII and (b) peak XII., Figure S9. LC chromatogram of quinic acid derivations 8-10 and 22., Figure S10. LC chromatogram of crude extract P1E and MS profiles of sugars, Figure S11. MPLC chromatogram of fraction P1B., Figure S12. MPLC chromatogram of fraction P1C2., Figure S13. MPLC chromatogram of sub-fraction P1C2-2., Figure S14. MPLC chromatogram of sub-fraction P1E3.

Author Contributions: Conceptualization, G.T.M.B. investigation, G.T.M.B. and D.U.K.K.; methodology, G.T.M.B. and J.G.K.; resources, B.N.L. and N.S.; supervision, N.S.; validation, I.K.S. and A.S.N.; writing—original draft, G.T.M.B.; writing—review and editing, N.S. All authors have read and agreed upon the final version of the manuscript.

Funding: The project was funded by DAAD (German Academic Exchange Service, project ID 57316173) in the frame of the Yaoundé-Bielefeld Graduate School of Natural Products with Antiparasite and Antibacterial Activities (YaBiNaPA, www.yabinapa.de). Coverage of the publication costs by the Open Access Publication Fund of Bielefeld University is gratefully acknowledged.

Data Availability Statement: The raw data supporting the conclusions of this article will be made available by the authors, without undue reservation, to any qualified researcher

Acknowledgments: The NMR and mass spectrometry service units at Bielefeld University are gratefully acknowledged.

Conflicts of Interest: The authors declare that they have no competing interests. The funders had no role in the design of the study; in the collection, analyses or interpretation of data; in the writing of the manuscript or in the decision to publish the results.

Sample Availability: Samples of the compounds are not available from the authors.

\section{References}

1. Jakupovic, J.; Jia, Y.; Zdero, C.; Warning, U.; Bohlmann, F.; Jones, S. Germacranolides from Elephantopus species. Phytochemistry 1987, 26, 1467-1469. [CrossRef]

2. Wang, Y.; Zhang, J.; Huang, Z.; Huang, X.-H.; Zheng, W.-B.; Yin, X.-F.; Li, Y.-L.; Li, B.; He, Q.-Y. Isodeoxyelephantopin induces protective autophagy in lung cancer cells via Nrf2-p62-keap1 feedback loop. Cell Death Dis. 2017, 8, e2876. [CrossRef]

3. Ooi, K.L.; Muhammad, T.S.T.; Lam, L.Y.; Sulaiman, S.F. Cytotoxic and Apoptotic Effects of Ethyl Acetate Extract of Elephantopus mollis Kunth. in Human Liver Carcinoma HepG2 Cells Through Caspase-3 Activation. Integr. Cancer Ther. 2012, 13, NP1-NP9. [CrossRef] [PubMed]

4. But, P.P.-H.; Hon, P.-M.; Cao, H.; Che, C.-T. A New Sesquiterpene Lactone fromElephantopus mollis. Planta Medica 1996, 62, 474-476. [CrossRef]

5. Wu, Z.-N.; Zhang, Y.-B.; Chen, N.-H.; Li, M.-J.; Li, M.-M.; Tang, W.; Zhuang, L.; Li, Y.-L.; Wang, G.-C. Sesquiterpene lactones from Elephantopus mollis and their anti-inflammatory activities. Phytochemistry 2017, 137, 81-86. [CrossRef] [PubMed]

6. Kabiru, A.; Por, L.Y. Elephantopus Species: Traditional Uses, Pharmacological Actions and Chemical Composition. Adv. Life Sci. Technol. 2013, 15, 6-13. 
7. Daisy, P.; Jasmine, R.; Ignacimuthu, S.; Murugan, E. A novel Steroid from Elephantopus scaber L. an Ethnomedicinal plant with antidiabetic activity. Phytomedicine 2009, 16, 252-257. [CrossRef] [PubMed]

8. Bitchagno, G.T.M.; Nchiozem-Ngnitedem, V.-A.; Wandji, N.T.; Noulala, G.C.T.; Fobofou, S.A.T.; Lenta, B.N. Plant-Derived Compounds against Microbial Infections and Cancers. In Bioactive Compounds in Nutraceutical and Functional Food for Good Human Health; IntechOpen: London, UK, 2021.

9. Da Silva, L.A.; Sandjo, L.P.; Misturini, A.; Caramori, G.F.; Biavatti, M.W. ESI-QTof-MS characterization of hirsutinolide and glaucolide sesquiterpene lactones: Fragmentation mechanisms and differentiation based on $\mathrm{Na}+/ \mathrm{H}+$ adducts interactions in complex mixture. J. Mass Spectrom. 2019, 54, 915-932. [CrossRef]

10. Mbougnia, J.F.T.; Bitchagno, G.T.M.; Wouamba, S.C.N.; Jouda, J.-B.; Awouafack, M.D.; Tene, M.; Lenta, B.N.; Kouam, S.F.; Tane, P.; Sewald, N. Two new triterpenoid fatty acid esters from Schefflera barteri Harms (Araliaceae). Nat. Prod. Res. 2020, 1-12. [CrossRef]

11. Mbougnia, J.F.; Happi, G.M.; Bitchagno, G.T.; Awouafack, M.D.; Lenta, B.N.; Kouam, S.F.; Tane, P.; Sewald, N.; Tene, M. Chemical constituents from Ficus natalensis hochst (Moraceae) and their chemophenetic significance. Biochem. Syst. Ecol. 2021, 95, 104227. [CrossRef]

12. Chouna, H.S.D.; Bankeu, J.J.K.; Fongang, Y.S.F.; Dize, D.; Ponou, B.K.; Bitchagno, G.T.M.; Awantu, A.F.; Lenta, B.N.; Fekam, F.B.; Ngouela, S.A.; et al. Constituents of Peperomia vulcanica Baker \& C. H. Wright (Piperaceae) with antiparasitic activity. Phytochem. Lett. 2021, 41, 14-20. [CrossRef]

13. Tabopda, T.K.; Ngoupayo, J.; Liu, J.; Ali, M.S.; Khan, S.N.; Ngadjui, B.T.; Luu, B. Further Cytotoxic Sesquiterpene Lactones from Elephantopus mollis KUNTH. Chem. Pharm. Bull. 2008, 56, 231-233. [CrossRef]

14. Pollora, G.C.; Bardon, A.; Catalan, C.A.; Griffin, C.L.; Herz, W. Elephantopus-type sesquiterpene lactones from a second Vernonanthura species, Vernonanthura lipeoensis. Biochem. Syst. Ecol. 2004, 32, 619-625. [CrossRef]

15. Tabopda, T.K.; Liu, J.; Ngadjui, B.T.; Luu, B. Cytotoxic Triterpene and Sesquiterpene Lactones from Elephantopus mollis and Induction of Apoptosis in Neuroblastoma Cells. Planta Medica 2007, 73, 376-380. [CrossRef] [PubMed]

16. Guo, W.; Wang, L.; Gao, Y.; Zhao, B.; Wang, D.; Duan, W.; Yu, Z. Isolation of isochlorogenic acid isomers in flower buds of Lonicera japonica by high-speed counter-current chromatography and preparative high performance liquid chromatography. J. Chromatogr. B 2015, 981-982, 27-32. [CrossRef] [PubMed]

17. Zhu, X.; Zhang, H.; Lo, R. Phenolic Compounds from the Leaf Extract of Artichoke (Cynara scolymusL.) and Their Antimicrobial Activities. J. Agric. Food Chem. 2004, 52, 7272-7278. [CrossRef] [PubMed]

18. Tian, Y.; Liu, X.-Q.; Dong, J.-X. [Apigenin glycosides from Euphorbia humifusa wild]. Acta Pharm. Sin. 2009, 44, 496-499.

19. Seelinger, G.; Merfort, I.; Schempp, C.M. Anti-Oxidant, Anti-Inflammatory and Anti-Allergic Activities of Luteolin. Planta Medica 2008, 74, 1667-1677. [CrossRef]

20. Harborne, J.B.; Williams, C.A. Flavonoid patterns in leaves of the gramineae. Biochem. Syst. Ecol. 1976, 4, 267-280. [CrossRef]

21. Stanikunaite, R.; Khan, S.I.; Trappe, J.M.; Ross, S.A. Cyclooxygenase-2 inhibitory and antioxidant compounds from the truffleElaphomyces granulatus. Phytotherapy Res. 2009, 23, 575-578. [CrossRef]

22. Jiang, L.; Zhang, S.; Xuan, L. Oxanthrone C-glycosides and epoxynaphthoquinol from the roots of Rumex japonicus. Phytochemistry 2007, 68, 2444-2449. [CrossRef]

23. Evans, F.E.; Miller, D.W.; Cairns, T.; Baddeley, G.V.; Wenkert, E. Carbon-13 nuclear magnetic resonance spectroscopy of naturally occurring substances. Part 74. Structure analysis of proximadiol (cryptomeridiol) by carbon-13 NMR spectroscopy. Phytochemistry 1982, 21, 937-938. [CrossRef]

24. Bitchagno, G.T.M.; Schueffler, A.; Simo, I.K.; Krumb, M.; Tane, P.; Opatz, T. Neo-clerodane diterpenoids from Conyza pyrrhopappa Sch.Bip. ex A.Rich. Nat. Prod. Res. 2019, 1-10. [CrossRef] [PubMed]

25. Tolonen, A.; Joutsamo, T.; Mattlla, S.; Kämäräinen, T.; Jalonen, J. Identification of Isomeric Dicaffeoylquinic Acids from Eleutherococcus senticosus using HPLC-ESI/ToF/MS and H-NMR Methods. Phytochem. Anal. 2002, 13, 316-328. [CrossRef] [PubMed]

26. Téllez-Martínez; Taboada, J.; González-Diddi, M. Cytotoxicity of some sesquiterpene lactones "in vitro". Arch. Invest. Med. 1980, $11,435-443$.

27. Zidorn, C. Plant chemophenetics-A new term for plant chemosystematics/plant chemotaxonomy in the macro-molecular era. Phytochemistry 2019, 163, 147-148. [CrossRef] [PubMed]

28. Ooi, K.L.; Muhammad, T.S.T.; Tan, M.L.; Sulaiman, S.F. Cytotoxic, apoptotic and anti- $\alpha$-glucosidase activities of 3,4-di-O-caffeoyl quinic acid, an antioxidant isolated from the polyphenolic-rich extract of Elephantopus mollis Kunth. J. Ethnopharmacol. 2011, 135, 685-695. [CrossRef]

29. Kabeer, F.A.; Prathapan, R. Phytopharmacological Profile of Elephantopus scaber. Pharmacology 2014, 5, 272-285. [CrossRef]

30. Kuete, V.; Fokou, F.W.; Karaosmanoğlu, O.; Beng, V.P.; Sivas, H. Cytotoxicity of the methanol extracts of Elephantopus mollis, Kalanchoe crenata and 4 other Cameroonian medicinal plants towards human carcinoma cells. BMC Complement. Altern. Med. 2017, 17, 280. [CrossRef] [PubMed]

31. Li, H.; Li, M.; Wang, W.; Shao, F.; Chen, W.; Xia, C.; Wang, S.; Li, Y.; Zhou, G.; Liu, Z. EM23, A natural sesquiterpene lactone from Elephantopus mollis, induces apoptosis in human myeloid leukemia cells through thioredoxin and reactive oxygen spe-cies-mediated signaling pathways. Front. Pharmacol. 2016, 7, 77. [CrossRef]

32. Fuchino, H.; Koide, T.; Takahashi, M.; Sekita, S.; Satake, M. New Sesquiterpene Lactones from Elephantopus mollis and Their Leishmanicidal Activities. Planta Medica 2001, 67, 647-653. [CrossRef] [PubMed] 
33. Li, Y.; Ye, W.; Wu, X.; Wang, G.; Wang, Y.; Zhang, X.; Zhang, D. Elephantopus Scaber Extract, Its Preparation Method and Application in Preparing Antiviral Medicine. China, CN 102219687A, 22 April 2011.

34. Nguemo, R.T.; Mbouangouere, R.; Bitchagno, G.T.M.; Tchuenguem, R.; Temgoua, E.V.N.; Ndontsa, B.L.; Mpetga, J.S.; Opatz, T.; Ngouela, A.S.; Tane, P. A new ceramide from the leaves of Lannea schimperi (Hochst. ex A.Rich.). Engl. Nat. Prod. Res. 2020, 8, 1-8. [CrossRef] [PubMed] 